\title{
PARA ALÉM DE MERAS PRESUNÇÕES, SÃO OS SERVIDORES PÚBLICOS RESISTENTES A MUDANÇAS?
}

\author{
BEYOND MERE ASSUMPTIONS, ARE PUBLIC WORKERS \\ RESISTANT TO CHANGE?
}

\section{ADEMÁS DE MERAS PRESUNCIONES, SON LOS SERVIDORES PÚBLICOS RESISTENTES A LOS CAMBIOS?}

Jefferson Menezes de Oliveira

Doutorando em Administração na Universidade Federal de Santa Maria (UFSM), Brasil

jeffersonmenezes@gmail.com

Vania de Fátima Barros Estivalete

Pós-doutora em Sociologia Econômica das

Organizações pela Universidade de Lisboa, Portugal /

Doutora em Agronegócios pela Universidade Federal do

Rio Grande do Sul (UFRGS), Brasil / Professora do

Programa de Pós-Graduação em Administração da

Universidade Federal de Santa Maria (UFSM), Brasil

vaniaestivalete@ufsm.br

\section{Gilnei Luiz de Moura}

Doutor em Administração pela Escola de Economia, Administração e Contabilidade da Universidade de São Paulo (USP), Brasil / Professor do Programa de PósGraduação em Administração da Universidade Federal de Santa Maria (UFSM), Brasil

mr.gmoura.ufsm@gmail.com

\section{Simone Alves Pacheco de Campos}

Doutora em Administração pela Universidade Federal do Rio Grande do Sul (UFRGS), Brasil / Professora do Programa de Pós-Graduação em Administração da Universidade Federal de Santa Maria (UFSM), Brasil simone.campos@ufsm.br
Contextus

ISSNe 2178-9258

Organização: Comitê Científico Interinstitucional Editor Científico: Carlos Adriano Santos Gomes Avaliação: double blind review pelo SEER/OJS

Recebido em 18/06/2017

Aceito em 08/12/2017

$2^{a}$ versão aceita em 20/12/2017

\section{RESUMO}

A fim de questionar a crença de que os servidores públicos são prevalentemente resistentes à mudança, este artigo teve por objetivo mensurar o nível de resistência a mudanças entre servidores públicos lotados em uma instituição federal de ensino localizada na região sul do Brasil. Para além de meras presunções, buscou-se elucidar os tipos proeminentes de atitudes frente a mudanças por meio de uma survey realizada junto a 207 servidores da instituição. Os resultados da avaliação possibilitaram desmistificar uma visão tradicionalista das organizações públicas, segundo a qual os servidores são taxados de resistentes à mudança. $\mathrm{Na}$ instituição pesquisada, observou-se abertura e aceitação à mudança como princípio central. Além disso, o estudo contribuiu para amortecer crenças de que servidores com mais idade são mais resistentes, bem como de que os técnico-administrativos são mais resistentes em relação aos docentes. 
Palavras-chave: Mudança. Resistência. Organizações públicas. Comportamento organizacional. Survey.

\begin{abstract}
In order to question the belief that public servants are predominantly resistant to change, this study intended to measure the level of resistance to change among public servants of a federal education institution located in Brazil's south. To overcome presumptions, we sought to elucidate the prominent types of attitudes towards change by means of a survey applied to 207 staff members of the institution. The results of the evaluation made it possible to demystify a traditionalist view of public organizations, according to which public servants are considered resistant to change. In the institution studied, there was openness and acceptance to change as a central principle. In addition, the study has contributed to cushion beliefs both that older staff members resist more and that technicians do more than teachers.
\end{abstract}

Keywords: Change. Resistance. Public organizations. Organizational behavior. Survey.

\title{
RESUMEN
}

A fin de cuestionar la creencia de que los servidores públicos son prevalentemente resistentes al cambio, este artículo tuvo por objetivo medir el nivel de resistencia a cambios entre servidores públicos de una institución federal de enseñanza localizada en la región sur de Brasil. Además de meras presunciones, se buscó elucidar los tipos prominentes de actitudes frente a cambios por medio de una encuesta realizada junto a 207 servidores de la institución. Los resultados de la evaluación posibilitaron desmitificar una visión tradicionalista de las organizaciones públicas, por la cual los servidores son considerados resistentes al cambio. En la institución investigada, se observó apertura y aceptación al cambio como principio central. Además, el estudio contribuyó a amortiguar creencias de que los servidores con más edad son más resistentes y de que los técnico-administrativos son más resistentes que los docentes.

Palabras clave: Cambio. Resistencia. Organizaciones públicas. Comportamiento organizacional. Encuesta.

\section{INTRODUÇÃO}

$\mathrm{Na}$ atualidade, profissionais das mais variadas áreas estão enfrentando mudanças substanciais em seu ambiente de atuação, tais como modificações nas demandas e preferências dos clientes/cidadãos, novas tecnologias e restrição orçamentária (NOORDEGRAAF, 2015a; 2015b). O processo de mudança causa incertezas que afetam os indivíduos psicologicamente, podendo provocar resistência, sendo esta uma das principais barreiras à mudança bem-sucedida nas organizações (FREIRES et al. 2014).

Quando os atores organizacionais percebem qualquer transformação de forma ameaçadora, podem comprometer os esforços de inovação da gestão organizacional ao adotarem comportamentos de resistência ou indiferença às mudanças propostas (PIETRO, 2001).

As heranças institucionais do setor público, do qual a organização foco deste estudo faz parte, levam ao surgimento de 
várias crenças em relação ao Estado e à administração pública. As ideias que enfatizam ineficiência, corrupção e interesse pessoal dos servidores em detrimento do bem comum e dos interesses da sociedade civil levam à construção de uma espécie de imaginário coletivo de ausência de perspectivas, de que tudo tem permanecido igual e nada mudará (SCHOMMER, 2003).

Em organizações públicas, na visão de Bergue (2010), a atuação das pessoas no ambiente organizacional ocorre segundo procedimentos de trabalho de caráter relativamente estável, ou seja, conforme uma sucessão de atividades que consome recursos e gera um resultado pretendido, marcados por um sensível grau de continuidade. Mais uma vez, no imaginário coletivo, esta inferência pode ser interpretada como causadora de resistência a mudanças entre os servidores públicos.

Nesse sentido, o presente artigo tem por objetivo mensurar o nível de resistência a mudanças entre servidores públicos lotados em uma Instituição Federal de Ensino localizada na região sul do Brasil. Justifica-se o estudo pela aplicação em um tipo de organização - a pública - que muitas vezes é mistificada pelo comportamento "resistente" de seus servidores. Assim, a presente abordagem servirá de base para elucidar os tipos proeminentes de atitudes de servidores públicos frente a mudanças, para além de meras presunções.

Na próxima seção, serão abordados os pressupostos teóricos relacionados a mudanças organizacionais e resistência a mudanças, os quais embasaram o estudo. Na seção seguinte, tratam-se dos aspectos metodológicos relacionados à coleta $\mathrm{e}$ análise dos dados, para posteriormente (seção quatro) apresentar a análise e a discussão dos resultados. Por fim, na seção cinco, são apresentadas as considerações finais, bem como sugestões para pesquisas futuras.

\section{FUNDAMENTAÇÃO TEÓRICA}

A presente seção dedica-se à apresentação do delineamento teórico norteador do estudo. São abordados conceitos relativos à mudança organizacional e resistência a mudanças, além da apresentação de modelos para mensuração da resistência.

\subsection{Mudanças organizacionais}

O filósofo grego Heráclito, citado por Morgan (1986), ressaltou que "não se pode pisar duas vezes o mesmo rio, já que as águas continuam constantemente rolando". Ele foi um dos primeiros filósofos, há quase 2.400 anos, a idealizar 
que o universo se encontra em contínua transformação, incorporando tanto características de permanência quanto de mudança. Depreende-se, conforme Bortolotti (2010), que nada é certo, exceto a mudança.

O caráter multidimensional do conceito de mudança é aqui trazido por Wood et al. (2000), os quais a definem como qualquer transformação de natureza estrutural, estratégica, cultural, tecnológica, humana ou de qualquer outro componente capaz de gerar impacto em partes ou no conjunto da organização.

Lima e Bressan (2003), no mesmo entendimento, apontam que a mudança organizacional é qualquer modificação nos componentes organizacionais formais $e$ informais mais relevantes, entre os quais: pessoas, estruturas, produtos, processos e cultura e que tenha por objetivo a melhoria do desempenho organizacional em resposta às demandas internas e externas.

De acordo com Neiva (2004), mudanças organizacionais são alterações, planejadas ou não, em componentes que caracterizam a organização como um todo, tais como finalidade básica, pessoas, trabalho, estrutura formal, cultura, relação da organização com o ambiente, decorrentes de fatores internos e/ou externos à organização, que trazem alguma consequência, positiva ou negativa, para os resultados organizacionais ou para sua sobrevivência.

Wood Jr. (2004) aponta que as mudanças organizacionais podem ser classificadas:

- Quanto à natureza: mudanças estruturais (organograma, funções); estratégicas (mercado-alvo, foco); culturais (valores, estilos de liderança); tecnológicas (processos, métodos de produção); relacionadas a recursos humanos (pessoas, políticas de seleção);

- Quanto à relação da organização com o meio ambiente: respostas às mudanças no ambiente ocorridas (reativas, determinísticas), ou uma antecipação baseada em expectativas (voluntária);

- Quanto à forma de implementação: re-educativa, coercitiva ou racional.

Robbins (2004), defende que a mudança pode ser analisada a partir de duas perspectivas distintas. A primeira compara um processo de mudança a um mar turbulento e desconhecido, o que torna impossível prever futuros obstáculos, sendo que a mudança é um estado natural e contínuo. $\mathrm{Na}$ segunda perspectiva, a organização é comparada a um mar calmo, que vez ou outra se depara com uma tormenta, cuja ocorrência leva à realização de alguns ajustes e a viagem prossegue 
tranquilamente, sendo esses ajustes os processos de mudança pelos quais as organizações passam. Na segunda visão, a mudança é considerada uma resposta à quebra do status quo, necessária apenas em determinadas situações.

Vale ressaltar que o processo de mudança varia de acordo com o modelo que o iniciou. Sendo assim, a mudança pode ser categorizada em três modelos: (1) quando a mudança começa por meio de uma decisão consciente de interferir na realidade; (2) quando o processo de mudança é iniciado como uma resposta planejada para problemas organizacionais; e (3) quando a mudança é considerada como um processo contínuo de aprendizagem (MOTTA, 1997).

Tabela 1 - Definições de resistência a mudança

\subsection{Resistência a mudanças}

A resistência é apresentada como a maior dificuldade de se implementar uma mudança, e muitos esforços são dedicados a procurar meios para superar essa resistência (GREY, 2003).

Entre as primeiras abordagens sobre o termo resistência à mudança destaca-se a de Kurt Lewin (1947), o qual defende a tese de que esta seria caracterizada pela tendência de um indivíduo ou um grupo de ir contra as forças que querem estabelecer um novo ponto de equilíbrio, necessário em razão do caos gerado pela mudança. E essa resistência ocorre nos indivíduos pelo fato de serem, concretamente, o alvo dessas forças de reequilíbrio.

Segundo Bortolotti (2010), várias conceituações diferentes de resistência foram relacionadas ao longo dos anos. Freires (2012) elenca alguns conceitos, conforme exposto na Tabela 1.

\begin{tabular}{l|l}
\hline Autores & Definições \\
\hline Costee (1999) & $\begin{array}{l}\text { Energias e poderes opostos que objetivam impedir, reduzir ou parar } \\
\text { mudanças com propósitos positivos ou negativos. }\end{array}$ \\
\hline Labianca et al. (2000) & $\begin{array}{l}\text { Barreiras cognitivas para qualquer tentativa de aumentar o poder entre } \\
\text { trabalhadores e gestão. }\end{array}$ \\
\hline Piderit (2000) & $\begin{array}{l}\text { Atitude para mudança que consiste em três componentes: cognitivo, } \\
\text { afetivo e comportamental. }\end{array}$ \\
\hline Bovey \& Hede (2001) & $\begin{array}{l}\text { Ações físicas ou mentais de apoio ou oposição a qualquer processo de } \\
\text { mudança organizacional. }\end{array}$
\end{tabular}




\begin{tabular}{l|l} 
(CONTINUAÇÃO) & \\
George \& Jones (2001) & $\begin{array}{l}\text { Resulta da interação dinâmica entre cognição e afeto durante o processo } \\
\text { de mudança individual. }\end{array}$ \\
\hline Ford et al. (2002) & $\begin{array}{l}\text { Resposta à mudança social como realidade construída derivada de } \\
\text { sucessos e fracassos. }\end{array}$ \\
\hline Zell (2003) & $\begin{array}{l}\text { Sistemas humanos que mantém a ordem existente, para evitar fortes } \\
\text { sentimentos desencadeados pela mudança. }\end{array}$ \\
\hline Val \& Fuentes (2003) & $\begin{array}{l}\text { Qualquer tentativa ou esforço de inércia para tentar manter o status quo } \\
\text { ou dificultar a mudança. }\end{array}$ \\
\hline
\end{tabular}

Fonte: Freires (2012), adaptado de Ritbumroong (2006).

Destaca-se o conceito de Piderit (2000), pelo qual resistência à mudança é definida como uma atitude ambivalente na resposta inicial do funcionário para com a mudança. A autora empregou a visão tridimensional de atitudes da psicologia social ao considerar resistência à mudança como sendo uma atitude, incluindo componentes afetivos, comportamentais e cognitivos.

A dimensão afetiva ou emocional envolve sentimentos e emoções de um indivíduo na resposta à mudança (como revolta, ansiedade, medo). A dimensão comportamental ou intencional, refere-se a um plano ou resolução de tomar alguma ação, isto é, apoiar ou opor-se, com base em comportamentos passados, ou intenções futuras de agir em relação ao objeto (mudança). A dimensão cognitiva, por fim, refere-se às avaliações do indivíduo e as consequentes crenças sobre a mudança e os efeitos da mudança, consistindo no que ele pensa (essa mudança é necessária? será benéfica?). Essas avaliações e crenças poderiam ser positivas ou negativas, calmas ou extremas, ou mesmo, neutras. (PIDERIT, 2000).

Os três componentes não são independentes um do outro, e o que as pessoas sentem sobre uma mudança frequentemente corresponderá com o que elas pensam sobre a própria e com respeito a suas intenções comportamentais. Entretanto, os componentes são distintos uns dos outros e cada um evidencia um aspecto diferente do fenômeno resistência. Conhecer as reações ambivalentes para a mudança permite aos gestores gerar novas ideias e soluções para lidar com a situação que incitou a iniciar mudança (OREG, 2006).

Para Oreg (2006), a resistência à mudança tem sido reconhecida há muito tempo como uma resposta inevitável e um fator importante que pode influenciar no sucesso ou no esforço de mudança organizacional. É empregada frequentemente na literatura sobre a mudança organizacional como uma 
explicação do porquê dos esforços para introduzir mudanças em larga escala em tecnologia, métodos de produção, práticas gerenciais ou sistema de compensação são de poucas expectativas ou fracassam.

As atitudes e as ações tomadas pelo indivíduo diante de um processo de mudança referem-se à sua percepção do processo e de suas consequências, a qual pode ocorrer em três fases: seleção de estímulos, organização de estímulos e interpretação perceptual (HERNANDEZ; CALDAS, 2001).

De acordo com Feldman (2005), mesmo quando as pessoas estão muito dispostas a mudar, a resistência pode surgir. A resistência, aferida pela autora em seu estudo, cresceu quando funcionários se encontraram numa situação que inibia a adoção dos recursos que achavam adequados para a realização do seu trabalho. Compreender o papel dos recursos em resistência pode ajudar a gerir a resistência que emerge.

Nesse sentido, a resistência à mudança trata-se de um fenômeno multifacetado, sendo possível pensar em uma situação em que haja resistência à mudança até mesmo quando as pessoas têm vantagem com ela. No entanto, isso não permite a sustentação da ideia de que a mudança é necessariamente, e com frequência, uma demonstração de recusa irracional àquilo que é vantajoso às pessoas (GREY, 2003).

\subsection{Instrumentos para mensurar a resistência a mudanças}

A fim de garantir o sucesso da implementação de uma mudança organizacional, seria importante ter uma avaliação de quanto os funcionários são resistentes à mudança, pois as mudanças organizacionais dependem da cooperação humana para se ter sucesso (BORTOLOTTI, 2010).

Nesse sentido, alguns instrumentos foram criados para avaliar a resistência a mudanças nas organizações. Citados por Bortolotti (2010), estão relacionados os estudos de Giangrecco (2002), Oreg (2003;2006) e Neiva, Ros e Paz (2004).

Giangrecco (2002) ofereceu uma sistemática conceitual para a resistência à mudança operacionalizada por meio de 13 itens. A escala desenvolvida foi nomeada de Resistance to Change (RTC).

Oreg (2003) desenvolveu uma escala para avaliar a inclinação dispositiva de um indivíduo resistir à mudança, também denominada Resistance to Change Scale (RTC). Ao incorporar as visões de Piderit (2000), em 2006, Oreg testou um modelo teórico de resistência à mudança considerando-a uma construção subjetiva, 
complexa e tridimensional. Ainda assim, verificou-se que a escala (RTC) levou em consideração apenas $\mathrm{o}$ aspecto de disposição, em vez de atitude diante da mudança, como preceituado por Piderit (2000).

Neiva, Ros e Paz (2004) propuseram e validaram uma escala para avaliação de atitudes frente à mudança organizacional. Nesta escala, os autores verificaram três fatores - ceticismo, temores e aceitação que representam as atitudes típicas apresentadas pelos indivíduos em situação de mudança organizacional, mas não fornece uma medida de resistência à mudança.

Bortolotti (2010), ao ponderar os estudos de Piderit (2000) e Oreg (2006), considera que a resistência é uma atitude, contendo os componentes afetivos, cognitivos e comportamentais. Nesse sentido, permite-se capturar a complexidade deste fenômeno e, portanto, oferecer uma melhor compreensão da resistência com seus antecedentes, suas causas e consequências.

A medida de resistência à mudança organizacional proposta por Bortolotti (2010), apresenta um indicativo que é definido por três tipos de comportamentos que podem ser observados frente às inovações organizacionais (FREIRES, 2012). São eles:
1) Nível de Aceitação: Envolve as variáveis resiliência psicológica, participação,

recompensa

intrínseca, abertura à experiência e confiança na gerência e compreende os três componentes (afetivo, cognitivo $e$ comportamental). Este nível é caracterizado pela capacidade que o indivíduo possui em aceitar as inovações mesmo quando submetido à pressão da empresa e, ainda, ter motivação ao acreditar que tem estabilidade emocional para lidar com tais mudanças. Confia que as modificações têm por objetivo trazer melhorias para empresa. Neste sentido, o indivíduo gosta de participar e cooperar com as mudanças, costuma se adaptar e ter disposição para promover e colaborar com elas, manifestando interesse em ganhar novas experiências.

2) Nível de Indiferença: Compreende as variáveis participação e abertura $\grave{a}$

experiência e é representado pelos componentes comportamental $e$ afetivo. Este nível é caracterizado por não haver interesse do indivíduo nas mudanças, este faz apenas o que é necessário e solicitado, devido à 
indiferença e apatia com relação à inovação,

além de não se sentir compromissado com a mesma. Tem preferência por rotinas $\mathrm{e}$ quer sempre fazer a mesma atividade.

3) Nível de (passiva/ativa):

(a) Passiva: Incluem as variáveis participação e abertura à experiência (componente comportamental e cognitivo). $\mathrm{O}$ indivíduo neste nível apresenta desinteresse pelas modificações que estão ocorrendo na empresa, de maneira que evita qualquer atividade gerada por ela e atua sem compromisso. (b) Ativa: Abrange as variáveis participação, abertura à experiência,

medo e confiança na gerência (componente cognitivo, afetivo $e$ comportamental).

Este nível é caracterizado pela lentidão do indivíduo em realizar o trabalho, reclama da gerência, apoia ações contra as mudanças, acredita que estas são negativas e procura maneiras de impedir que elas aconteçam por meio de manipulações e, também, as evitam por medo do novo.

Salienta-se, por fim, que medir diretamente a resistência à mudança é impossível, então, para se obter uma medida desta variável latente é necessário o uso de variáveis secundárias que estejam relacionadas com ela. Nesse sentido, as respostas aos itens do instrumento validado por Bortolotti (2010) são utilizadas para desenvolver estimativas das reações e formas de comportamento dos indivíduos frente à mudança organizacional, permitindo aferir a resistência dos mesmos.

\section{MÉTODO}

Com caráter descritivo, o estudo foi conduzido pelo método survey, indicado para a coleta de dados primários quando se necessita informações de um amplo número de pessoas (HAIR et al., 2005). A população foco foi representada pelos servidores públicos lotados em uma instituição federal de ensino localizada no estado do Rio Grande do Sul/Brasil.

A amostra da pesquisa foi não probabilística, constituída a partir da acessibilidade

do pesquisador. Participaram 207 servidores públicos lotados na instituição pesquisada, integrantes das carreiras docente e técnica-administrativa, regidos 
pela lei $\mathrm{n}^{\circ} 8.112 / 1990$, com vínculo efetivo (concursados).

Como instrumento de coleta de dados, utilizou-se um questionário composto de duas seções. Enquanto a primeira foi composta por variáveis sócio demográficas e profissionais, tais como gênero, faixa etária e tempo de serviço na instituição (itens 1 a 8 ), a segunda foi composta pelas variáveis relativas ao modelo validado por Bortolotti (2010), a Escala de Resistência à Mudança (itens 9 a 30).

O instrumento foi elaborado por Bortolotti (2010) para medir o nível de resistência à mudança de funcionários dentro de contextos organizacionais. Seus 22 itens buscam identificar três níveis proeminentes diante da mudança: aceitação, indiferença e resistência à mudança. Além disso, uma vez que a resistência é considerada uma atitude, o modelo explora os componentes afetivos, cognitivos e comportamentais dentre os níveis. Os itens do instrumento, originalmente, são respondidos em escala de quatro pontos, apresentando os seguintes extremos: $1=$ Discordo fortemente e $4=$ Concordo fortemente (FREIRES, et al. 2014). A Tabela 2 demonstra a forma como os itens foram distribuídos no questionário.

Tabela 2 - Itens do instrumento de coleta de dados

\begin{tabular}{|c|c|c|c|}
\hline Níveis & Variáveis & Itens & Componentes \\
\hline \multirow{5}{*}{ Aceitação } & Resiliência psicológica & 22,24 & \multirow{5}{*}{$\begin{array}{l}\text { Componente afetivo }(20,25) \\
\text { Componente cognitivo }(19,22) \\
\text { Componente comportamental }(10,24,28,9,18)\end{array}$} \\
\hline & Participação & $10,18,28$ & \\
\hline & Recompensa intrínseca & 20 & \\
\hline & Abertura à experiência & 9,25 & \\
\hline & Confiança na gerência & 19 & \\
\hline \multirow[t]{2}{*}{ Indiferença } & Participação & 15,30 & \multirow{2}{*}{$\begin{array}{l}\text { Componente afetivo }(16,30) \\
\text { Componente comportamental }(15,27)\end{array}$} \\
\hline & Abertura à experiência & 16,27 & \\
\hline \multirow[t]{8}{*}{ Resistência } & Passiva: & & \multirow[t]{3}{*}{ Componente comportamental $(17,26,12)$} \\
\hline & Participação & 17,26 & \\
\hline & Abertura à experiência & 12 & \\
\hline & Ativa: & & \multirow{5}{*}{$\begin{array}{l}\text { Componente comportamental }(11,13,14,23,29) \text {. } \\
\text { Componente cognitivo (21) }\end{array}$} \\
\hline & Participação & $11,13,14$ & \\
\hline & Abertura à experiência & 21 & \\
\hline & Medo & 29 & \\
\hline & Confiança na gerência & 23 & \\
\hline
\end{tabular}

Fonte: adaptado de Bortolotti (2010).

Conforme sinalizam Vieira e Dalmoro (2013), as respostas ao instrumento foram adaptadas para uma escala tipo likert de 5 pontos de modo a permitir o ponto neutro e melhor se ajustar 
a respondentes com diferentes níveis de habilidade.

O questionário foi operacionalizado na base de dados Google Docs, a qual permite aos usuários criar e editar formulários online para interação entre pesquisador e pesquisado em tempo real. Para que atraísse o interesse dos possíveis entrevistados, o instrumento de coleta foi disseminado por meio de e-mails e links em grupos específicos da instituição em redes sociais. Dessa forma, foi possível coletar dados com agilidade e confiabilidade, pois o sistema Google Docs estrutura as respostas de forma sistêmica e na íntegra. A coleta ocorreu entre 31 de outubro e 20 de novembro de 2016.

Após coletados, os dados foram analisados com o apoio do software SPSS (Statistical Package for the Social Sciences). Primeiramente, foram realizadas análises estatísticas relacionadas às variáveis sócio demográficas e profissionais, a fim de traçar o perfil dos respondentes. Na sequência, foi aplicada a análise fatorial para explorar os dados do modelo adotado. O método de análise fatorial empregado foi o dos componentes principais, no qual se leva em conta a variância total dos dados, buscando-se encontrar estruturas comuns (MALHOTRA, 2012).
Para conformação da amostra, a partir da Teoria Clássica de Medidas (TCM), foram realizados os seguintes passos: (i) Medida de adequação da amostra de Kaiser-Meyer-Oikin (KMO); (ii) Teste de Esfericidade de Bartlett; (iii) Comunalidades; (iv) Cargas fatoriais; (v) Autovalor e; (vi) Variância total atribuída a cada fator (MALHOTRA, 2012). Uma vez identificados os resultados da análise fatorial, calculou-se a confiabilidade para os fatores obtidos por meio do Alpha de Cronbach, indicador de consistência interna, com o propósito de averiguar a confiabilidade dos construtos teóricos encontrados. Por fim, por meio do teste de diferenças de médias, foi possível comparar os resultados encontrados entre grupos distintos na pesquisa.

\section{ANÁLISE E DISCUSSÃO DOS RESULTADOS}

A presente seção apresenta os resultados encontrados na pesquisa, abarcando o perfil dos pesquisados e as análises referentes a resistência a mudanças, explorada a partir do modelo adotado.

\subsection{Perfil dos pesquisados}

Para o conhecimento da amostra pesquisada, foram realizados os testes estatísticos descritivos e de frequência para 
as variáveis sócio demográficas e profissionais, contidas nos itens 1 a 8 do instrumento de coleta de dados. Fizeram parte da amostra 207 servidores, lotados e em exercício na instituição em estudo. A Tabela 3 apresenta os resultados encontrados.

Tabela 3 - Perfil dos pesquisados

\begin{tabular}{|c|c|c|c|}
\hline \multicolumn{2}{|c|}{ Gênero } & \multicolumn{2}{|c|}{ Categoria Funcional } \\
\hline Masculino & $83(40,1 \%)$ & Docente & $83(40,1 \%)$ \\
\hline Feminino & $124(59,9 \%)$ & Técnico-administrativo & $124(59,9 \%)$ \\
\hline \multicolumn{2}{|c|}{ Idade } & \multicolumn{2}{|c|}{ Escolaridade (Nível completo ou incompleto) } \\
\hline Entre 18 e 26 anos & $9(4,3 \%)$ & Ensino Médio & $3(1,4 \%)$ \\
\hline Entre 27 e 35 anos & $56(27,1 \%)$ & Ensino Superior (Graduação) & $18(8,7 \%)$ \\
\hline Entre 36 e 44 anos & $49(23,7 \%)$ & Pós-Graduação (Especialização, & $186(89,9 \%)$ \\
\hline Entre 45 e 53 anos & $59(28,5 \%)$ & Mestrado ou Doutorado) & \\
\hline 54 ou mais anos & $34(16,4 \%)$ & & \\
\hline \multicolumn{2}{|c|}{ Tempo de Serviço na Instituição } & \multicolumn{2}{|l|}{ Estado Civil } \\
\hline Até 5 anos & $66(31,9 \%)$ & Casado (a) ou união estável & $142(68,6 \%)$ \\
\hline Entre 6 e 10 anos & $56(27,1 \%)$ & Solteiro (a) & $45(21,7 \%)$ \\
\hline Entre 11 e 15 anos & $16(7,7 \%)$ & Separado (a) ou divorciado (a) & $14(6,8 \%)$ \\
\hline Entre 16 e 20 anos & $9(4,3 \%)$ & Viúvo (a) & $4(1,9 \%)$ \\
\hline 21 ou mais anos & $60(29 \%)$ & Outro & $2(1 \%)$ \\
\hline \multicolumn{2}{|c|}{ Tem Filhos } & \multicolumn{2}{|c|}{ Ocupante de Cargo de Chefia } \\
\hline Sim & $118(57 \%)$ & Sim & $55(26,6 \%)$ \\
\hline Não & $89(43 \%)$ & Não & $152(73,4 \%)$ \\
\hline
\end{tabular}

Fonte: dados da pesquisa.

Quanto ao gênero, observou-se prevalência do feminino $(59,9 \%)$ em relação ao masculino $(40,1 \%)$. No que concerne a faixa etária dos pesquisados, $4,3 \%$ possuem entre 18 e 26 anos, $27,1 \%$ possuem entre 27 e 35 anos, 23,7\% possuem entre 36 e 44 anos, 28,5\% possuem entre 45 e 53 anos e, com 54 ou mais anos de idade somaram $16,4 \%$ dos respondentes. Houve prevalência do estado civil casado (a) ou união estável $(68,6 \%)$, bem como da existência de filhos (57\%).
Por ser uma instituição de ensino, no que tange à formação, destacou-se o domínio de pós-graduação entre os pesquisados $(89,9 \%)$. No que se refere à categoria funcional, $40,1 \%$ exercem cargos docentes, enquanto que $59,9 \%$ exercem cargos técnico-administrativos. Entre os pesquisados, 26,6\% exercem cargos de chefia e o tempo de exercício na instituição variou, sobretudo entre aqueles que possuem até 5 anos de tempo de serviço $(31,9 \%)$ e aqueles com 21 ou mais anos $(29 \%)$ 


\subsection{Mensuração no nível de resistência a mudanças}

Entre os itens n. 9 a 30 do instrumento de coleta de dados estavam dispostos os 22 itens destinados à mensuração do nível de resistência a mudanças, abarcando os níveis: aceitação, indiferença e resistência (BORTOLOTTI, 2010). Inicialmente, a exploração dos dados referente à escala incluiu a aplicação dos testes estatísticos: Medida de Adequação da Amostra de Kaiser-Meyer-Olkin (KMO) e Teste de Esfericidade de Bartlett. O primeiro deverá ser maior ou igual a 0,6 para que a correlação entre cada par de variáveis seja explicada pelas demais variáveis do estudo, conforme Pestana e Gageiro (2005), sendo satisfatório o resultado obtido $(0,889)$. O segundo teste interroga a hipótese de que as variáveis não sejam correlacionadas na população (MALHOTRA, 2012), sendo no caso, o resultado significativo (sig 0,000). Ambos os testes, portanto, evidenciaram a adequação do uso da análise fatorial.

Para a análise fatorial das 22 variáveis do instrumento utilizado, com o intuito de verificar possíveis agregações entre as mesmas, de modo a associá-las em fatores comuns, optou-se por adotar a análise de componentes principais como método de extração das dimensões e a
Varimax como método de rotação. Foram considerados 3 fatores na extração, os quais apresentaram autovalores superiores a 1,0, atendendo a um percentual de variância explicada de 60,35\%. Em análise às comunalidades, percebeu-se que as variáveis $11,17,19,21,22,24,27$ e 29 apresentaram índices inferiores a 0,5, revelando que não estão sendo adequadamente explicadas pela solução fatorial. Entre as sugestões apresentadas por Hair et al. (2009), optou-se pela exclusão gradual dessas variáveis de forma a obter uma especificação do modelo com 14 variáveis.

Para verificar a confiabilidade dos fatores encontrados, utilizou-se teste de confiabilidade Alpha de Cronbach, o qual, segundo Pestana e Gageiro (2005), varia entre 0 e 1 , sendo tanto melhor quanto maior a sua proximidade da unidade. Consoante o valor do alfa é possível classificar a consistência interna, sendo que para um alfa inferior a 0,6, esta é inaceitável. A consistência interna é fraca quando o alfa assume um valor entre 0,6 e 0,7; razoável para um alfa entre 0,7 e 0,8 ; boa quando o alfa está entre a 0,8 e 0,9 ; e, muito boa quando o valor do alfa é superior a 0,9 . Segue-se com as análises das cargas fatoriais representadas na Tabela 4 . 
Tabela 4 - Análise fatorial exploratória da escala de resistência à mudança

\begin{tabular}{|c|c|c|c|}
\hline \multicolumn{4}{|c|}{ Fator 1 - Aceitação - Alpha de Cronbach = 0,844 } \\
\hline $\mathbf{I}$ & Descrição & Nível Original & Carga \\
\hline 10 & Coopero ativamente para realizar a mudança quando ela acontece. & Aceitação & 0,793 \\
\hline 20 & Se mudanças são implementadas no meu trabalho, gosto de participar delas. & Aceitação & 0,760 \\
\hline 28 & Estou disposto a colaborar para promover mudanças no meu trabalho. & Aceitação & 0,713 \\
\hline 25 & $\begin{array}{l}\text { Gostaria de ganhar novas experiências provenientes de mudanças no meu } \\
\text { trabalho. }\end{array}$ & Aceitação & 0,700 \\
\hline 09 & Sou capaz de me adaptar às mudanças quando elas ocorrem. & Aceitação & 0,698 \\
\hline 18 & Sinto que tenho entusiasmo para lidar com mudanças no meu trabalho. & Aceitação & 0,659 \\
\hline \multicolumn{4}{|c|}{ Fator 2 - Indiferença e passividade - Alpha de Cronbach $=0,779$} \\
\hline $\mathbf{I}$ & Descrição & Nível Original & Carga \\
\hline 15 & Quando mudanças acontecem, procuro fazer somente o que é necessário. & Indiferença & 0,727 \\
\hline 12 & $\begin{array}{l}\text { Tento evitar as responsabilidades adicionais decorrentes de mudanças em meu } \\
\text { trabalho. }\end{array}$ & $\begin{array}{l}\text { Resistência } \\
\text { (Passiva) }\end{array}$ & 0,709 \\
\hline 16 & Prefiro ficar indiferente às mudanças. & Indiferença & 0,643 \\
\hline 30 & Se mudanças acontecem, não me sinto comprometido. & Indiferença & 0,599 \\
\hline 26 & Não estou interessado em realizar atividades que resultarão em mudanças. & $\begin{array}{l}\text { Resistência } \\
\text { (Passiva) }\end{array}$ & 0,556 \\
\hline \multicolumn{4}{|c|}{ Fator 3 - Resistência ativa - Alpha de Cronbach = 0,676 } \\
\hline $\mathbf{I}$ & Descrição & Nível Original & Carga \\
\hline 14 & $\begin{array}{l}\text { Apoio as ações dos meus colegas contra mudanças que ocorrem no meu } \\
\text { trabalho. }\end{array}$ & $\begin{array}{l}\text { Resistência } \\
\text { (Ativa) }\end{array}$ & 0,737 \\
\hline 13 & $\begin{array}{l}\text { Na iminência de uma mudança no meu trabalho, procuro formas de impedir } \\
\text { que ela venha acontecer. }\end{array}$ & $\begin{array}{l}\text { Resistência } \\
\text { (Ativa) }\end{array}$ & 0,680 \\
\hline 23 & Quando ocorrem mudanças encontro motivos para me queixar da chefia. & $\begin{array}{l}\text { Resistência } \\
\text { (Ativa) }\end{array}$ & 0,651 \\
\hline
\end{tabular}

Fonte: dados da pesquisa.

Com boa consistência interna (Alfa $=0,844)$ e, explicando $38,78 \%$ da variância dos dados, o primeiro fator foi nomeado de Aceitação, apoiando-se na exclusividade de assertivas associadas ao nível de aceitação diante da mudança (6 itens).

Com razoável consistência interna (Alfa $=0,779)$ e, explicando $13,22 \%$ da variância dos dados, o segundo fator foi nomeado de Indiferença e passividade, na medida em que incluiu três assertivas relacionadas ao nível de indiferença e duas assertivas relacionadas ao nível de resistência passiva diante da mudança.
Acredita-se que a associação de níveis tenha ocorrido pela interpretação de indiferença que as assertivas relacionadas à resistência passiva obtiveram. Assim, as inferências "Tento evitar as responsabilidades adicionais decorrentes de mudanças em meu trabalho" e Não estou interessado em realizar atividades que resultarão em mudanças", originalmente relativas ao nível de resistência, expressam passividade, podem estar associadas à compreensão de indiferença diante da mudança.

Por fim, com fraca consistência interna (Alfa $=0,676)$ e, explicando 8,34\% da variância dos dados, o terceiro fator 
incluiu três assertivas originalmente estabelecidas para aferir a resistência ativa diante da mudança, motivo pelo qual foi denominado de Resistência ativa.

Vale especificar a nova distribuição das assertivas originárias do modelo de Bortolotti (2010), a partir dos níveis, variáveis e componentes já apresentados na Tabela 2. Após a análise fatorial exploratória, tem-se na Tabela 5 a nova especificação das 14 assertivas remanescentes.

Tabela 5 - Nova especificação das assertivas após a análise fatorial exploratória

\begin{tabular}{|c|c|c|c|}
\hline Níveis / Fatores & Variáveis & Itens & Componentes \\
\hline \multirow{3}{*}{ Aceitação } & Participação & $10,18,28$ & \multirow{3}{*}{$\begin{array}{l}\text { Componente afetivo }(20,25) \\
\text { Componente comportamental }(10,28,9,18)\end{array}$} \\
\hline & Recompensa intrínseca & 20 & \\
\hline & Abertura à experiência & 9,25 & \\
\hline \multirow{6}{*}{$\begin{array}{l}\text { Indiferença e } \\
\text { passividade }\end{array}$} & Indiferença: & & \multirow{3}{*}{$\begin{array}{l}\text { Componente afetivo }(16,30) \\
\text { Componente comportamental }(15)\end{array}$} \\
\hline & Participação & 15,30 & \\
\hline & Abertura à experiência & 16 & \\
\hline & \multicolumn{2}{|l|}{ Resistência passiva: } & \multirow[t]{3}{*}{ Componente comportamental $(26,12)$} \\
\hline & Participação & 26 & \\
\hline & Abertura à experiência & 12 & \\
\hline \multirow[t]{2}{*}{ Resistência ativa } & Participação & 13,14 & \multirow[t]{2}{*}{ Componente comportamental $(13,14,23)$. } \\
\hline & Confiança na gerência & 23 & \\
\hline
\end{tabular}

Fonte: dados da pesquisa.

Conforme demonstra a Tabela 5, no fator de Aceitação permanecem dispostos os indicadores Participação, Recompensa intrínseca e Abertura à experiência, estando envolvidos os componentes afetivo e comportamental. A participação (itens 10,18 e 28) tem sido verificada em muitas pesquisas como um elemento que está relacionado com a resistência à mudança, isto é, pessoas que tem a oportunidade de participar nas decisões da mudança estão mais favoráveis em aceitá-la. A recompensa intrínseca (item 20) está relacionada com autodeterminação, isto é, pode-se conseguir a recompensa intrínseca quando são satisfeitas necessidades. A abertura à experiência (itens 9 e 25) verifica se os indivíduos gostam ou buscam novas experiências ou novidades e também se possuem capacidade para adaptarem-se as mudanças (BORTOLOTTI, 2010).

No fator Indiferença e passividade, relativamente ao nível de indiferença, permanecem dispostos os indicadores Participação e Abertura à experiência, estando envolvidos os componentes afetivo e comportamental. Na participação (itens 15 e 30), é avaliado o comportamento de fazer somente o necessário, bem como o 
comprometimento com a mudança. A abertura à experiência (item 16) busca verificar se o indivíduo tem uma postura apática, de indiferença em relação à mudança. Relativamente à resistência passiva, permanecem dispostos, também, os indicadores Participação e Abertura à experiência, envolvendo o componente comportamental. A participação (item 26) mensura o desinteresse em realizar atividades que resultarão em mudanças enquanto que a abertura à experiência (item 12) avalia o evitamento de responsabilidades adicionais decorrentes de mudanças (BORTOLOTTI, 2010).

Por fim, no fator Resistência ativa, permanecem dispostos os indicadores Participação e Confiança na gerência, estando envolvido o componente comportamental. Nesse sentido, a participação (itens 13 e 14), avalia a intenção de apoiar e realizar ações que impeçam a mudança. Relativamente à confiança na gerência, o item 23 avalia a predisposição em reclamar da chefia quando ocorrem mudanças (BORTOLOTTI, 2010).

Diante do estabelecimento dos fatores, a fim de analisar os dados indicados acerca da resistência a mudanças entre os servidores da instituição pesquisada, calculou-se a média e o desvio padrão dos itens, conforme apresenta a Tabela 6 .

Tabela 6 - Médias e desvio padrão da escala de resistência à mudança

\begin{tabular}{|c|c|c|c|}
\hline \multicolumn{4}{|c|}{ Fator 1 - Aceitação - Alpha de Cronbach = 0,844 } \\
\hline I & Descrição & Média & Desvio \\
\hline 10 & Coopero ativamente para realizar a mudança quando ela acontece. & 4,149 & 0,745 \\
\hline 20 & Se mudanças são implementadas no meu trabalho, gosto de participar delas. & 4,144 & 0,805 \\
\hline 28 & Estou disposto a colaborar para promover mudanças no meu trabalho. & 4,212 & 0,904 \\
\hline 25 & Gostaria de ganhar novas experiências provenientes de mudanças no meu trabalho. & 4,082 & 0,918 \\
\hline 09 & Sou capaz de me adaptar às mudanças quando elas ocorrem. & 4,173 & 0,723 \\
\hline 18 & Sinto que tenho entusiasmo para lidar com mudanças no meu trabalho. & 3,806 & 0,986 \\
\hline \multicolumn{4}{|c|}{ Fator 2 - Indiferença e passividade - Alpha de Cronbach $=0,779$} \\
\hline $\mathbf{I}$ & Descrição & Média & Desvio \\
\hline 15 & Quando mudanças acontecem, procuro fazer somente o que é necessário. & 2,120 & 1,132 \\
\hline 12 & $\begin{array}{l}\text { Tento evitar as responsabilidades adicionais decorrentes de mudanças em meu } \\
\text { trabalho. }\end{array}$ & 2,067 & 1,112 \\
\hline 16 & Prefiro ficar indiferente às mudanças. & 1,864 & 1,043 \\
\hline 30 & Se mudanças acontecem, não me sinto comprometido. & 1,724 & 0,890 \\
\hline 26 & Não estou interessado em realizar atividades que resultarão em mudanças. & 1,850 & 0,940 \\
\hline \multicolumn{4}{|c|}{ Fator 3 - Resistência ativa - Alpha de Cronbach $=0,676$} \\
\hline I & Descrição & Média & Desvio \\
\hline 14 & Apoio as ações dos meus colegas contra mudanças que ocorrem no meu trabalho. & 1,9614 & 1,069 \\
\hline 13 & $\begin{array}{l}\text { Na iminência de uma mudança no meu trabalho, procuro formas de impedir que ela } \\
\text { venha acontecer. }\end{array}$ & 1,7101 & 0,855 \\
\hline 23 & Quando ocorrem mudanças encontro motivos para me queixar da chefia. & 1,5942 & 0,781 \\
\hline
\end{tabular}

Fonte: dados da pesquisa. 
Considerando a escala $-1=$ discordo fortemente a $5=$ concordo fortemente observa-se que, no fator aceitação, as médias das variáveis, com exceção da 18 , foram superiores a 4,00, indicando a prevalência de concordância em relação às assertivas.

Em relação ao fator indiferença $e$ passividade, as médias das cinco variáveis ficaram próximas de 2,00, indicando a prevalência de discordância em relação às assertivas.
Por fim, em relação ao fator resistência ativa, as médias das três variáveis ficaram abaixo de 2,00, indicando, também, a prevalência de discordância em relação às assertivas. Nesse sentido, tornase plausível o estudo das frequências em relação aos níveis de concordância com as assertivas. A Tabela 7 apresenta os resultados.

Tabela 7 - Concordância em relação às assertivas (\%)

\begin{tabular}{|c|c|c|c|c|c|c|}
\hline \multicolumn{7}{|c|}{ Fator 1 - Aceitação } \\
\hline I & Descrição & DF & D & I & $\mathbf{C}$ & $\mathbf{C F}$ \\
\hline 10 & $\begin{array}{l}\text { Coopero ativamente para realizar a mudança quando ela } \\
\text { acontece. }\end{array}$ & 0 & 1,4 & 16,9 & 46,9 & 34,8 \\
\hline 20 & $\begin{array}{l}\text { Se mudanças são implementadas no meu trabalho, gosto de } \\
\text { participar delas. }\end{array}$ & 0,5 & 2,9 & 14,5 & 45,9 & 36,2 \\
\hline 28 & $\begin{array}{l}\text { Estou disposto a colaborar para promover mudanças no meu } \\
\text { trabalho. }\end{array}$ & 2,4 & 1,9 & 12,1 & 39,1 & 44,4 \\
\hline 25 & $\begin{array}{l}\text { Gostaria de ganhar novas experiências provenientes de } \\
\text { mudanças no meu trabalho. }\end{array}$ & 1 & 4,3 & 19,3 & 36,2 & 39,1 \\
\hline 09 & Sou capaz de me adaptar às mudanças quando elas ocorrem. & 0,5 & 1,4 & 11,6 & 53,1 & 33,3 \\
\hline 18 & $\begin{array}{l}\text { Sinto que tenho entusiasmo para lidar com mudanças no meu } \\
\text { trabalho. }\end{array}$ & 2,4 & 6,3 & 26,6 & 37,7 & 27,1 \\
\hline & Avaliação média & 1,1 & 3 & 16,8 & 43,2 & 35,8 \\
\hline \multicolumn{7}{|c|}{ Fator 2 - Indiferença e passividade } \\
\hline $\mathbf{I}$ & Descrição & DF & D & $\mathbf{I}$ & $\mathbf{C}$ & CF \\
\hline 15 & $\begin{array}{l}\text { Quando mudanças acontecem, procuro fazer somente o que é } \\
\text { necessário. }\end{array}$ & 37,7 & 30,4 & 16,9 & 12,1 & 2,9 \\
\hline 12 & $\begin{array}{l}\text { Tento evitar as responsabilidades adicionais decorrentes de } \\
\text { mudanças em meu trabalho. }\end{array}$ & 38,6 & 32,4 & 15,9 & 9,7 & 3,4 \\
\hline 16 & Prefiro ficar indiferente às mudanças. & 47,8 & 28,5 & 16,4 & 3,9 & 3,4 \\
\hline 30 & Se mudanças acontecem, não me sinto comprometido. & 49,3 & 34,8 & 12,1 & 1,9 & 1,9 \\
\hline 26 & $\begin{array}{l}\text { Não estou interessado em realizar atividades que resultarão em } \\
\text { mudanças. }\end{array}$ & 44 & 34,3 & 15,9 & 4,3 & 1,4 \\
\hline & Avaliação média & 43,5 & 32,1 & 15,4 & 6,4 & 2,6 \\
\hline \multicolumn{7}{|c|}{ Fator 3 - Resistência ativa } \\
\hline $\mathbf{I}$ & Descrição & DF & D & $\mathbf{I}$ & $\mathbf{C}$ & $\mathbf{C F}$ \\
\hline 14 & $\begin{array}{l}\text { Apoio as ações dos meus colegas contra mudanças que ocorrem } \\
\text { no meu trabalho. }\end{array}$ & 43,5 & 28,5 & 20,3 & 3,9 & 3,9 \\
\hline
\end{tabular}


(CONTINUAÇÃO)

\begin{tabular}{c|l|c|c|c|c|c}
13 & $\begin{array}{l}\text { Na iminência de uma mudança no meu trabalho, procuro } \\
\text { formas de impedir que ela venha acontecer. }\end{array}$ & $\mathbf{4 9 , 8}$ & $\mathbf{3 3 , 8}$ & 13 & 2,4 & 1 \\
\hline 23 & $\begin{array}{l}\text { Quando ocorrem mudanças encontro motivos para me queixar } \\
\text { da chefia. }\end{array}$ & $\mathbf{5 4 , 6}$ & $\mathbf{3 4 , 8}$ & 8,2 & 1,4 & 1 \\
\hline Avaliação média & $\mathbf{4 9 , 3}$ & $\mathbf{3 2 , 4}$ & 13,8 & 2,6 & 2 \\
\hline
\end{tabular}

Legenda: $\mathrm{DF}=$ discordo fortemente; $\mathrm{D}=$ discordo; $\mathrm{I}=$ indiferente; $\mathrm{C}=$ concordo; $\mathrm{CF}=$ concordo fortemente. Fonte: dados da pesquisa.

No que tange ao fator Aceitação, observa-se que, em média, $79 \%$ dos respondentes concordam ou concordam fortemente com as assertivas. Tal índice revela a proeminência de aceitação diante da mudança, indicando que a maioria dos servidores coopera ativamente $(81,7 \%)$, gosta de participar $(82,1 \%)$, está disposto a colaborar $(83,5 \%)$, gostaria de ganhar novas experiências provenientes de mudanças (75,3\%), é capaz de se adaptar $(86,4 \%)$ e tem entusiasmo em lidar com mudanças no seu trabalho $(64,8 \%)$.

Quanto ao fator Indiferença $e$ passividade, em média, $75,6 \%$ dos respondentes discordam ou discordam fortemente com as assertivas. Esse quantitativo revela que as atitudes de indiferença ou comportamento passivo não estão manifestados entre a maioria dos respondentes. Apenas 15\% dos respondentes concordam ou concordam fortemente que procuram fazer somente o necessário diante de mudanças. Quanto às responsabilidades adicionais provenientes de mudanças, $13,1 \%$ concordam ou concordam fortemente que buscam evitálas. Questionados sobre a indiferença diante da mudança, 7,3\% dos servidores indicam esse comportamento. Quando mudanças acontecem, apenas 3,8\% dos pesquisados afirmam não apresentar comprometimento. Por fim, neste fator, $5,7 \%$ do total de servidores indicam o desinteresse em atividades que resultarão em mudanças.

Por fim, quanto ao fator Resistência ativa, identificou-se o maior índice médio de discordância $(84,4 \%)$, incluindo aqueles que discordam ou discordam fortemente. Esse quantitativo revela o baixo interesse dos servidores em retaliar possíveis mudanças. Considerando os pontos concordo ou concordo fortemente, apenas $2,4 \%$ busca queixar-se da chefia quando ocorrem mudanças, $3,4 \%$ procura formas de impedir que elas ocorram e 7,8\% apoia ações de colegas contra mudanças.

Diante do exposto, os resultados da avaliação possibilitaram desmistificar uma visão tradicionalista das organizações públicas, pela qual os servidores são taxados de resistentes à mudança. $\mathrm{Na}$ instituição pesquisada, observou-se abertura e aceitação a mudança como princípio central. Ainda assim, os gestores de equipes na instituição em estudo podem 
atentar para aquelas variáveis que indicaram certa indiferença ou resistência, ainda que em menores níveis, de forma a fundamentar estratégias para planos de mudança que minimizem focos de resistência.
Por fim, por meio do teste de diferenças de médias, julgou-se plausível a investigação sobre a comparação de resultados entre grupos distintos na pesquisa. A Tabela 8 apresenta os resultados encontrados.

Tabela 8 - Diferenças de médias na pesquisa

\begin{tabular}{|c|c|}
\hline Variável & Diferenças* \\
\hline Gênero & Não foram encontradas diferenças significativas entre feminino e masculino \\
\hline Idade & $\begin{array}{l}\text { Uma vez dividida a amostra em dois grupos [até } 44 \text { anos de idade }(55,1 \% \text { da amostra) e } 45 \text { ou } \\
\text { mais anos de idade (44,9\% da amostra)], foi encontrada diferença significativa no item } 25 \text { : } \\
\text { - } 25 \text {. Gostaria de ganhar novas experiências provenientes de mudanças no meu trabalho. } \\
\text { Média dos que possuem até } 44 \text { anos de idade: } 3,95 \\
\text { Média dos que possuem } 45 \text { ou mais anos de idade: } 4,25\end{array}$ \\
\hline $\begin{array}{l}\text { Tempo de } \\
\text { serviço na } \\
\text { instituição }\end{array}$ & $\begin{array}{l}\text { Uma vez dividida a amostra em dois grupos [tempo de até } 10 \text { anos ( } 59 \% \text { da amostra) e tempo } \\
\text { igual ou superior a } 11 \text { anos na instituição ( } 41 \% \text { da amostra) ], não foram encontradas diferenças } \\
\text { significativas. }\end{array}$ \\
\hline $\begin{array}{l}\text { Exercício de } \\
\text { chefia }\end{array}$ & $\begin{array}{l}\text { Não foram encontradas diferenças significativas entre ocupantes e não ocupantes de cargo de } \\
\text { chefia. }\end{array}$ \\
\hline $\begin{array}{l}\text { Categoria } \\
\text { funcional }\end{array}$ & $\begin{array}{l}\text { Diferenças significativas nos itens } 20,16,30 \text { e } 26 \text { : } \\
\text { 20. Se mudanças são implementadas no meu trabalho, gosto de participar delas. } \\
\text { Média dos técnico-administrativos: } 4,25 \\
\text { Média dos docentes: } 3,99 \\
\text { 16. Prefiro ficar indiferente às mudanças. } \\
\text { Média dos técnico-administrativos: } 1,74 \\
\text { Média dos docentes: } 2,05 \\
\text { - 30. Se mudanças acontecem, não me sinto comprometido. } \\
\text { Média dos técnico-administrativos: } 1,56 \\
\text { Média dos docentes: } 1,96 \\
\text { 26. Não estou interessado em realizar atividades que resultarão em mudanças. } \\
\text { Média dos técnico-administrativos: } 1,73 \\
\text { Média dos docentes: } 2,02\end{array}$ \\
\hline $\begin{array}{l}\text { Existência } \\
\text { de filhos }\end{array}$ & $\begin{array}{l}\text { Diferença significativa no item 10: } \\
\text { 10. Coopero ativamente para realizar a mudança quando ela acontece. } \\
\text { Média dos que possuem filhos: } 4,03 \\
\text { Média dos que não possuem filhos: } 4,30\end{array}$ \\
\hline Estado civil & $\begin{array}{l}\text { Não foram encontradas diferenças significativas entre solteiros e casados/união estável, } \\
\text { condições correspondentes a } 90,3 \% \text { da amostra. }\end{array}$ \\
\hline Escolaridade & Teste não realizado pela homogeneidade da amostra ( $89,9 \%$ com pós-graduação). \\
\hline \multicolumn{2}{|c|}{$\begin{array}{l}\text { * significância associada ao teste } t \text { inferior a } 0,05 \\
\text { Fonte: dados da pesquisa. }\end{array}$} \\
\hline \multicolumn{2}{|c|}{ Conforme pode ser visualizado na } \\
\hline \multicolumn{2}{|c|}{$\begin{array}{l}\text { Tabela } 8 \text {, não foram encontradas diferenças } \\
\text { significativas quanto ao gênero, quanto ao } \\
\text { exercício de chefia e, em relação estado } \\
\text { civil, também não foi encontrada diferença }\end{array}$} \\
\hline
\end{tabular}


média superior em relação aos servidores com menos de 45 anos no que tange à abertura para ganhar novas experiências decorrentes de mudanças no trabalho.

Em relação à categoria, o teste de diferença de médias demonstrou que os docentes apresentaram média inferior, em relação aos técnico-administrativos, no item 20, demostrando uma menor concordância com a intenção de participar nas mudanças. Nos itens 16, 30 e 26, ambos relativos ao fator de indiferença, os técnicoadministrativos obtiveram médias inferiores em relação aos docentes, demonstrando uma menor concordância com o comportamento de indiferença diante da mudança.

Quanto à existência de filhos, houve diferença significativa no item 10. A média dos que não possuem filhos foi superior à dos que possuem, demostrando que os primeiros cooperam mais, em média, para realizar a mudança de forma ativa.

$\mathrm{O}$ estudo, além de desmistificar a noção de resistência prevalente entre servidores públicos, com o teste de diferenças de médias, também rejeita duas situações presumidas na instituição: (i) de que os servidores com idade mais elevada são mais resistentes e; (ii) de que os técnicoadministrativos são mais resistentes do que os docentes.
Os resultados, em geral, vão ao encontro dos recentes achados de Cardoso e Mattos (2016), os quais mensuraram a resistência a mudanças em uma instituição federal de ensino do norte do Brasil. Estes autores identificaram que, na instituição pesquisada, além da prevalência de aceitação diante da mudança, observou-se que os servidores não percebem a mudança como algo a ser evitado, mas sim como um aspecto do cotidiano.

\section{CONSIDERAÇÕES FINAIS}

O estudo, além de identificar que os servidores pesquisados, em sua maioria, apresentam atitudes de aceitação diante das mudanças organizacionais, contribuiu por apontar as situações em que os sentimentos de indiferença e até mesmo resistência ativa estão presentes, ainda que em menor grau. Este fato possibilita que estratégias de mudança possam ser melhor formuladas pelos gestores da instituição.

A análise fatorial exploratória realizada a partir dos itens estabelecidos por Bortolotti (2010) permitiu a identificação de três fatores com índices aceitáveis de confiabilidade. No fator Aceitação, foi revelada a proeminência de concordância com a aceitação diante da mudança (79\%), indicando que a maioria dos servidores coopera ativamente, gosta de participar, 
está disposto a colaborar, gostaria de ganhar novas experiências provenientes de mudanças, é capaz de se adaptar, e tem entusiasmo em lidar com mudanças no seu trabalho. Quanto ao fator Indiferença $e$ passividade, em média, $75,6 \%$ dos respondentes discordam ou discordam fortemente com as assertivas, indicando que as atitudes de indiferença ou comportamento passivo não estão manifestados entre a maioria dos respondentes. Por fim, no fator Resistência Ativa, identificou-se o maior índice de discordância $(84,4 \%)$ em relação às assertivas, revelando o baixo interesse dos servidores em retaliar possíveis mudanças.

Além disso, o estudo foi efetivo em identificar diferenças significativas entre grupos respondentes ao instrumento. Os principais achados são de que os servidores docentes se mostraram mais resistentes se comparados aos servidores técnicoadministrativos e de que os servidores com idade mais elevada, se comparados aos mais jovens, apresentaram maior média no que tange à abertura para ganhar novas experiências decorrentes de mudanças no trabalho, desmistificando muitas presunções que permeiam o serviço público.

Salienta-se, porém, que devido à constituição de uma amostra não probabilística, os resultados do estudo não podem ser generalizados. Além disso, quanto às limitações encontradas, destacam-se os retornos qualitativos de alguns respondentes. Houve dificuldade em responder sobre mudanças de forma "geral”, pois, segundo três respondentes, é difícil tratar a mudança de forma "neutra", sem classificá-la de forma "positiva" ou "negativa". Segundo um respondente, é difícil o posicionamento diante de itens abstratos sobre a mudança, sem levar em conta seu contexto. Sendo assim, o campo para estudos futuros sobre a mensuração de resistência a mudanças organizacionais está aberto a reconstruções e sob diferentes paradigmas. 


\section{REFERÊNCIAS}

Bergue, S. T. Gestão de Pessoas em Organizações Públicas. $3^{\text {a }}$ Edição. Caxias do Sul: Educs, 2010.

BORTOLOTTI, S. L. Resistência à mudança organizacional: Medida de avaliação por meio da teoria da resposta ao item. Tese de Doutorado. Departamento de Engenharia de Produção, Universidade Federal de Santa Catarina, Florianópolis, SC, 2010.

CARDOSO, H. G. MATTOS, C. A. C. Avaliação da resistência à mudança organizacional: uma investigação em uma instituição federal de ensino superior. In: SemeAd, XIX, 2016, São Paulo, Anais...São Paulo: FEA/USP, 2016.

DALMORO, M. VIEIRA, K. M. Dilemas na construção de escalas Tipo Likert: o número de itens e a disposição influenciam nos resultados? Gestão Organizacional. Vol. 6 - Edição especial, 2013.

FELDMAN, Martha S. Resources in Emerging Structures and Processes of Change. Organization Science. Vol. 15, No. 3, 295-309, May-June 2004.

FREIRES, D. A. N., GOUVEIA, V. V., BORTOLOTTI, S. L. V., RIBAS, F. T. T. Resistência à mudança organizacional: Perspectiva valorativa e organizacional. Psico PUCRS, 45(4), 513 $523,2014$.

FREIRES, D. A. N. Resistência à mudança organizacional: Correlatos valorativos e organizacionais. Tese de Doutorado. Departamento de Psicologia, Universidade Federal da Paraíba, João Pessoa, PB, 2012.

GIANGRECO, A. Conceptualisation and Operationalisation of Resistance to Change. Liuc Papers n. 103, Série Econômica aziendale11, Suppl. Marzo, 2002.

GREY, C. The fetish of change. Tamara: Journal of Critical Postmodern Organization Science, 2(2): 1-19, 2003.

HAIR, J. F.; BLACK, W. C.; BABIN, B. J.; ANDERSON, R. E.; TATHAM, R. L. Análise multivariada de dados. 5. ed. Porto Alegre: Bookman, 2005.

HAIR. Jr.; CORRAR, L. J.; PAULO, E.; FILHO, J. M. D. Análise multivariada: para os cursos de administração, ciências contábeis e economia. São Paulo: Atlas, 2009. 
HERNANDEZ, J. M. C. CALDAS, M. P. Resistência à mudança: uma revisão crítica. Revista de Administração de Empresas, São Paulo, 41(2), 31-45, 2001.

LEWIN, K. Frontiers in group dynamics. Human Relations, New York, v. 1, n. 1, p. 5-41, 1947.

LIMA, S. M. V.; BRESSAN, C. L. Mudança organizacional: uma introdução. In: (Org.). Mudança organizacional: teoria e gestão. Rio de Janeiro: FGV, 2003.

MALHOTRA, N. K. Pesquisa de Marketing: uma orientação aplicada. $6^{\text {a }}$. Porto Alegre: Bookman, 2012.

MORGAN, G. Images of organization. Beverly Hills: Sage Publications, 1986.

NOORDegraAf, M. Public Management. Performance, Professionalism, and Politics. Basingstoke: Palgrave, 2015a.

NOORDEGRAAF, M. Hybrid professionalism and beyond. (New) forms of public professionalism in changing organizational and societal contexts. Journal of Professions and Organization, 2(2), 2015b.

PESTANA, M. H. GAGEIRO, J. N. (2005). Análise de Dados para Ciências Sociais - A Complementaridade do SPSS. Lisboa: Sílabo, 2005.

MORGAN, G. Imagens da organização. Editora Atlas, São Paulo, 1996.

MOTTA, P. R. Transformação organizacional: A teoria e a prática de inovar. 1. ed. Rio de Janeiro: Qualitymark, 1997.

NEIVA, E. R.; ROS, M.; PAZ, M. G. T. Validación de una escala de actitudes con relación al cambio organizacional. Revista de Psicología Organizacional y del Trabajo. vol. 20, núm. 1, pp. 9-30 2004.

NEIVA, E. R. Percepção de Mudança organizacional: o papel das atitudes e das características organizacionais. Tese de Doutorado, Universidade de Brasília, DF, Brasil, 2004.

OREG, S. Resistance to change: Developing an individual difference measure. Journal of Applied Psychology, 88, 680-693, 2003. 
OREG, S. Personality, context and resistance to organizational change. European Journal of Work and Organizational Psychology, 15, 73-101, 2006.

PIDERIT, S. K. Rethinking resistance and recognizing ambivalence: A multidimensional view of attitudes toward an organizational change. Academy of Management Review, 25(4), 783 $794,2000$.

PIETRO, M. S. Z. As novas regras para os servidores públicos. Rio de Janeiro: FUNDAP, 2001.

ROBBINS, S. P. Fundamentos do comportamento organizacional. 7. ed. São Paulo: Pearson Prentice Hall, 2004.

SCHOMER, P. Gestão Pública no Brasil: notícias do teatro de operações. Revista de administração de empresas, v. 43, n. 4, p. 102-107, 2003.

WOOD, T. JR.; CURADO, I. B.; CAMPOS, H. M. Vencendo a crise: mudança organizacional na Rhodia Farma. Revista de Administração de Empresas, v. 34, n. 5, p. 67-79, 1994.

WOOD T. JR (Coord.) Mudança Organizacional. 4 ed. São Paulo: Atlas, 2004. 